\title{
A Hayekian Explanation of Hayek's 'Epistemic Turn'
}

\author{
Scott Scheall, Department of Science, Technology, and Society, Arizona \\ State University, USA \\ scott.scheall@asu.edu
}

\begin{abstract}
The present essay aims to account for F.A. Hayek's oft-noted 'turn' away from technical economics to concerns of a more philosophical nature. In particular, the paper seeks an explanatory principle that reconciles various elements of both continuity and discontinuity in Hayek's intellectual development, especially with respect to the evolution of his arguments concerning economic fluctuations. The essay uncovers such an explanatory principle in Hayek's own methodology of sciences of complex phenomena. According to this principle, an inquirer who confronts phenomena too complex for adequate explanation on the basis of current knowledge must move to a more general, albeit less testable, explanation. This is precisely what occurred in the evolution of Hayek's thought concerning trade cycles. The concluding section considers the implications of the argument for the extensive secondary literature on Hayek's 'transformation'.
\end{abstract}

Keywords: Hayek, business cycle theory, methodology, complex phenomena, pattern prediction, explanation of the principle

\section{Continuity and Discontinuity in the Intellectual Development of F.A. Hayek}

It has been often noted - including by the man himself (Hayek, 1964b [1967], p. 91) - that F.A. Hayek's career as a 'very pure and narrow economic theorist' came to a rather abrupt end, sometime around the publication of 1941's The Pure Theory of Capital (Hayek, 1941 [2007]) and that his subsequent career led 'into all kinds of questions usually regarded as philosophical' (Hayek, 1964b [1967], p. 91). However, opinions differ concerning the exact nature and extent of what Bruce Caldwell $(1988 ; 2004)$ called 'Hayek's transformation'. Indeed, the questions about whether and which of Hayek's scientific, methodological, and philosophical attitudes were more or less continuous across the arc of his career remains perhaps the central issue in Hayek scholarship - what did Hayek give up, and what did he retain, when he 'transformed'? The secondary literature is rife with arguments concerning this or that aspect of Hayek's early writings that were purportedly rejected - or retained - over the course of the subsequent development of his ideas, and with attempts to draw more general conclusions concerning the unity of Hayek's thought from such vignettes.

I have made two, confessedly minor, contributions to this literature. My 'Hayek the Apriorist?' (Scheall, 2015a) argues against Terence Hutchison's (1981) well-known 'Hayek l'

\footnotetext{
1 Jack Birner (1999) coined the phrase 'epistemic turn' to describe (his own view of) Hayek's transformation. I have suggested elsewhere that 'Hayek's "epistemic turn" was less a turn than an enlargement of elements that were always present in his thought' (Scheall, 2015b, p. 103). Nonetheless, for reasons that should become clear as the argument of the paper progresses, I have adopted 'epistemic turn' rather than 'transformation' in the title of the essay.
} 
thesis that Hayek's early career in economics bore the mark of a commitment to methodological apriorism (the paper is largely silent concerning Hutchison's thesis that there was a Popperian 'Hayek II'). Elsewhere, I have argued that one can infer from several of Hayek's post-transformation writings an 'epistemic' theory of industrial fluctuations that is closely related to his famous business cycle theory of the interwar years (Scheall, 2015b). Both Hayek's earlier and later accounts attribute economic fluctuations to actors ignorant of knowledge required to prevent disequilibrating effects. However, I also emphasise in the latter paper certain discontinuities between the theoretical foundations of Hayek's interwar business cycle theory and his later 'epistemic' account.

In the present paper, I am less interested in contributing further to the already extensive literature on purported continuities and discontinuities in Hayek's intellectual development. Rather, my aim here is to find an explanatory principle that unifies seemingly disparate elements of Hayek's thought already uncovered in the literature. In particular, I'm looking for an explanation of both the continuities and discontinuities posited in the aforementioned 'Hayek's Epistemic Theory of Industrial Fluctuations' (Scheall, 2015b). The main thesis advanced in the present paper is that one can discover, in Hayek's own methodology of sciences of complex phenomena, an 'explanation of the principle' of both (a) the continuity concerning the causal role in propagating economic fluctuations of action based on an inadequate epistemic basis and (b) the discontinuity in the theories he adopted at different times to explain the sources, and disequilibrating economic effects, of action founded on deficient knowledge. In the concluding section, I discuss how this same principle might unify other seemingly irreconcilable continuities and discontinuities discussed in the existing secondary literature.

The present paper builds a Hayekian explanation of Hayek's epistemic turn ${ }^{2}$ upon the premises that 1) Hayek's early career was dedicated to the investigation of some very complex phenomena, namely, those of the business cycle, using the tools of technical economic analysis then available. ${ }^{3}$ Hayek thought that this project ultimately failed, at least in part, because the complexity of the relevant phenomena outran the explanatory capacities of these tools. 2) Hayek (1964a [1967], p. 29; also see 1961 [2014], p. 381-382) spent much of his subsequent career developing a methodology of sciences of complex phenomena, according to which the inquirer confronted with phenomena of a degree of complexity beyond explanatory tractability must take refuge in a system of 'higher-level generalities' that subsume some of the otherwise inexplicable complexities of the relevant phenomena. 3) Hayek's post-turn writings indicate that his thought had moved from the theoretical plane of

\footnotetext{
${ }^{2}$ Strictly speaking, the argument of the current paper contributes to an explanation of merely an aspect of Hayek's epistemic turn, i.e., the development of his thought concerning industrial fluctuations, and it is only insofar as this development is representative of his broader intellectual evolution that the argument contributes to an explanation of his 'transformation' or 'epistemic turn'. No very robust argument will be offered here for connecting the changes in his thought concerning fluctuations with his broader intellectual evolution. Indeed, quite the opposite - it is not for nothing that the phrase 'epistemic turn' appears in scare quotes in the paper's title. As we will see, it is probably impossible to explain more than particular aspects of Hayek's career, and any attempt to infer from such specific episodes some more general conclusion regarding the continuity of Hayek's thought is specious. It is (in part) the fact that the present paper both exemplifies and emphasises certain limitations on explanations of a scholar's intellectual development that distinguishes it from the remainder of the existing literature on Hayek's transformation.

3 'Technical economics' was Hayek's own term for what he took himself to be doing prior to the publication of 'Economics and Knowledge' (Hayek, 1937 [1948]): 'This brings me to what in my personal development was the starting point of all these reflections, and which may explain why, though at one time a very pure and narrow economic theorist, I was led from technical economics into all kinds of questions usually regarded as philosophical. When I look back, it seems to have all begun, nearly thirty years ago, with an essay on "Economics and Knowledge"' (Hayek, 1964b [1967], p. 91).
} 
generalities about the phenomena of industrial fluctuations, to the higher-level methodological plane of generalities about the latter kind of theoretical generalities.

In short, Hayek's methodology of sciences of complex phenomena contributes to an explanation of the development of his thought concerning industrial fluctuations. According to this methodology, an inquirer who runs into phenomena too complex for adequate explanation on the basis of current knowledge must move to a more general, albeit less testable, explanation. This is precisely what happened in the evolution of Hayek's thought concerning economic fluctuations.

\section{The Argument of 'Hayek's Epistemic Theory of Industrial Fluctuations' Revisited}

The current essay was originally conceived as part of a larger project that included my 'Hayek's Epistemic Theory of Industrial Fluctuations' (Scheall, 2015b). It was only relatively late in the development of this project that I split what was becoming a very long (and, thus, probably unpublishable) single essay into two stand-alone papers. Although these articles advance distinct theses, in order to appreciate the present paper, it is important to have some understanding of the argument of 'Hayek's Epistemic Theory', an essay that considers the development over some forty-plus years of Hayek's thought concerning economic fluctuations. ${ }^{4}$

I defend three theses in 'Hayek's Epistemic Theory', the most central being that, if one combines the main arguments of Hayek's 'Economics and Knowledge' (Hayek, 1937 [1948]), 'The Use of Knowledge in Society' (Hayek, 1945 [1948]), and 'The Pretence of Knowledge' (Hayek, 1975 [1978]), the result is a (sketch) of a theory that attributes industrial fluctuations to action based on deficient knowledge. More carefully, in 'Economics and Knowledge', Hayek (1937 [1948]) developed an epistemic conception of economic equilibrium - or, as he later preferred to call it, economic 'order' (Hayek, 1968 [1978]) - according to which 'equilibrium exists to the extent that economically-relevant beliefs of individual market participants are mutually consistent and accurate with respect to the external facts' (Scheall, 2015b, p. 115). The problem left unresolved in 'Economics and Knowledge' concerns the mechanism(s) by which the empirically observable tendency toward equilibrium in this epistemic sense is either facilitated or impeded. ${ }^{5}$ In 'The Use of Knowledge in Society', Hayek (1945 [1948]) argued that a system of freely adjusting prices is necessary to facilitate the tendency toward coordination of relevant beliefs. In the absence of exogenous interference, the price system qua epistemic mechanism operates - not perfectly, but well enough (Scheall, 2015b, p. 105, footnote 1) - to facilitate the tendency toward belief coordination. Finally, in his 1974 Nobel Prize lecture, Hayek (1975 [1978]) argued that policymakers do indeed regularly interfere with the price system. As I put the point in 'Hayek's Epistemic Theory',

"blinded by a false ["scientistic"] methodology, the economic policymaker is led into a "pretence of knowledge" upon which she acts, unawares - indeed, convinced otherwise - of the irrelevance and inadequacy of her epistemic position. Policymakers are misled into the false belief that they can possess both the theoretical and empirical knowledge required of effective

\footnotetext{
4 I use the terms industrial (economic) fluctuations, business (trade) cycles, and episodes of disequilibrium interchangeably despite certain differences in the technical meanings of these terms. I justify this stipulation at some length in 'Hayek's Epistemic Theory' (Scheall, 2015b, p. 102, footnote 2).

5 'Experience shows us that something of this sort does happen, since the empirical observation that prices tend to correspond to costs was the beginning of our science' (Hayek, 1937 [1948], p. 51).
} 
macroeconomic management by the combination of a methodology that accords special status to measurable parameters, a [Keynesian] theory that makes the relevant parameters those that just happen to be measurable, and the statistical techniques for the analysis of the aggregative variables in which the latter [Keynesian] theory trucks.

What's more, when policymakers pretend to possess the relevant economic knowledge and make policy on the basis of this pretence, their decisions typically impede, either directly or indirectly, the price system's knowledge-coordinating function. ${ }^{6}$ It suffices to hamper the operation of the tendency toward equilibrium for those in a position to do so to intervene on the basis of knowledge that they don't in fact possess in a way that fetters the adjustment of the price system to changes in economic circumstances. Such is Hayek's epistemic theory of industrial fluctuations' (Scheall, 2015b, p. 109).

Beyond defending this theory-sketch, I further argue in 'Hayek's Epistemic Theory' that ignorance plays a similar part in Hayek's famous early theory of the cycle as it does in his subsequent epistemic account. The problem of action in the economy on an inadequate epistemic basis is a motive for, and causal factor in, both accounts. The epistemic theory assigns ignorant action a general causal role in propagating fluctuations: dis-coordination will follow wherever the price system is exogenously manipulated (directly or indirectly) on the basis of knowledge inadequate to facilitate the epistemic function of freely-adjusting prices. It just so happens that, according to Hayek, it is policymakers who most often (and with comparatively more general, and thus, more dire consequences) interfere with the price system on a deficient epistemic basis. On the other hand, Hayek's early theory assigns ignorant action a more specific causal role in the cycle. In order to avoid industrial fluctuations, bankers must possess knowledge of the so-called 'natural' rate(s) of interest that would balance the supply of voluntary savings with the demand for loans. However, the natural rate cannot be known, so bankers cannot know, at any particular time, whether they are artificially increasing (or decreasing) the supply of loanable funds, i.e., expanding (or contracting) credit, beyond the supply of voluntary savings. Thus, it turns out that, despite certain fundamental discontinuities between the two theories, ${ }^{7}$ the earlier theory is a special case of the later, more general, epistemic account, at least with respect to the causal role that each theory assigns to action founded on deficient knowledge.

Thus, Hayek's concern for the economic effects of ignorant action remained continuous (and, indeed, only grew more general) throughout his multiple attempts to explain industrial fluctuations, but the foundations of these theories were markedly discontinuous. My concern in the present paper is to show that, in his methodology of sciences of complex phenomena, Hayek (consciously or otherwise) articulated a principle that explains both these continuities and discontinuities.

\footnotetext{
${ }^{6}$ Hayek had what l've called elsewhere a 'non-standard conception of knowledge' (Scheall, 2015c) according to which knowledge and belief are, unless otherwise qualified, synonymous.

7 The earlier theory is based on the standard Walrasian general equilibrium concept, while the later account starts from Hayek's epistemic treatment of economic order (née 'equilibrium'); the interwar theory incorporates the Böhm-Bawerkian treatment of capital from which the epistemic theory abstracts entirely.
} 


\section{The Implications of Hayek's Methodology of Sciences of Complex Phenomena for an Explanation of His 'Epistemic Turn'}

Hayek (1945 [1948], p. 80) argued that there are two varieties of knowledge: 'a little reflection will show that there is.... body of very important but unorganized knowledge which cannot possibly be called scientific in the sense of knowledge of general rules: the knowledge of the particular circumstances of time and place'. ${ }^{8}$ This distinction between theoretical knowledge (of 'general rules') and empirical knowledge (of 'particular circumstances of time and place') is essential to Hayek's methodology of sciences of complex phenomena. The possibility of a 'full' explanation or of a detailed prediction of particular events, ${ }^{9}$ requires that the inquirer possess both kinds of knowledge to a sufficient extent: '[s] uch prediction will be possible if we can ascertain...all the circumstances which influence those events. We need for this both a theory which tells us on what circumstances the events in question will depend, and information on the particular circumstances which may influence the event in which we are interested' (Hayek, 1961 [2014], pp. 376-377). ${ }^{10}$ In order to explain some phenomena, we need theoretical knowledge of the causal structure that gives rise to the phenomena and empirical knowledge of the values the causal elements assume at the relevant time and place. If our knowledge of both theory and data are 'full' relative to our explanatory purposes, we will be able to generate full explanations and precise predictions of particular events.

For Hayek, the sciences of complex phenomena were those disciplines in which this condition of epistemic adequacy does not hold. ${ }^{11}$ Complex phenomena consist of a large number of elements interconnected (both to each other and to the external environment) in such a way as to give rise to an emergent order that possesses 'certain general or abstract features which will recur independently of the particular values of the individual data, so long as the general structure...is preserved' (Hayek, 1964a [1967], p. 26). Naturally, given our cognitive limitations, as the elements (and, thus, their internal and external interconnections) grow in number, our ability to acquire theoretical knowledge of the structure from which the relevant order emerges, diminishes. Similarly, it becomes more difficult to acquire sufficient empirical knowledge of the relevant data given otherwise adequate theoretical knowledge. ${ }^{12}$ In the sciences of complex phenomena, because our knowledge of either theory or data (or both) is limited, we cannot generate full explanations or detailed predictions of particular

\footnotetext{
${ }^{8}$ See my 'Brief Note Concerning Hayek's Non-Standard Conception of Knowledge' (Scheall, 2015c) for more on Hayek's epistemology.

${ }^{9}$ Hayek accepted that explanations and predictions are logically symmetrical (Hayek, 1955 [1967], p. 9, footnote 4). I use the terms interchangeably.

${ }^{10}$ To say that an explanation is 'full' is not to say that it explains every aspect of the phenomena under investigation. According to Hayek (1952, p. 182), an explanation 'can never explain everything to be observed on a particular set of events'. Instead, explanatory 'fullness' should be thought of as sensitive to contextual considerations. An explanation that is full in one scientific context may be comparatively empty in another.

11 The sciences of complex phenomena include theoretical psychology (Hayek, 1952), economics, linguistics (Hayek, 1967, p. 72), geology, evolutionary biology, and the astrophysical sub-disciplines that investigate the formation of stars and galaxies (Hayek, 1967, p. 76); as well as 'cybernetics, the theory of automata or machines, general systems theory, and perhaps also communications theory' (Hayek, 1955 [1967], p. 20).

12 For his own part, Hayek emphasised what I call the 'data problem' in the sciences of complex phenomena, i.e., the difficulty of acquiring adequate empirical knowledge of the values taken by the causal elements at the relevant time and place. In 'Lesser Degrees of Explanation' (Scheall, 2015d), I argue that Hayek's methodology implies that the sciences of complex phenomena may also suffer from a distinct 'theory problem', i.e., the difficulty of acquiring adequate theoretical knowledge of the relevant causal elements, the internal interrelations between the proper subsets of these variables, and the external relations between the subsets of elements and the environment.
} 
events: we are limited to 'explanations of the principle' and 'pattern predictions' of greater or lesser 'degree'. ${ }^{13}$

All of this is to say that Hayek (1964a [1967], pp. 25-27) essentially defined the sciences of complex phenomena in terms of these epistemic difficulties. A full explanation of some complex phenomena requires a sufficiently complex model. ${ }^{14}$ This means that any attempt to theorise about complex phenomena as if they were simple - i.e., any attempt to use a simple model consisting of few variables to account for phenomena the adequate explanation of which require a complex model consisting of many variables - will ultimately fail. That is, Hayek's methodology predicts that we should observe patterns of failure wherever tools appropriate only for the analysis of simpler phenomena are applied to complex phenomena.

However, this does not mean that the scholar who encounters phenomena too complex for the extant analytical tools must throw up their hands in defeat. The answer to the problem of complexity, according to Hayek's methodology, is to develop a system of 'higherlevel theories' that subsume some of the otherwise inexplicable complexities of the relevant phenomena.

'Though we may never know as much about certain complex phenomena as we can know about simple phenomena, we may partly pierce the boundary by deliberately cultivating a technique which aims at more limited objectives-the explanation not of individual events but merely of the appearance of certain patterns or orders. Whether we call these mere explanations of the principle or mere pattern predictions or higher-level theories does not matter. Once we explicitly recognize that the understanding of the general mechanism which produces patterns of a certain kind is not merely a tool for specific predictions but important in its own right, and that it may provide important guides to action (or sometimes indications of the desirability of no action), we may indeed find that this limited knowledge is most valuable' (Hayek, 1964a [1967], p. 40).

As I will show in the next section, Hayek ultimately came to believe that the analytical tools he used in his early business cycle project were simply inadequate for the complexity of the phenomena he was trying to explain. Moreover, Hayek's epistemic theory of industrial fluctuations is precisely the sort of more general, higher-level, theory that, according to his methodology, a scholar must develop in order to deal with the problem of otherwise intractable complexity.

\footnotetext{
${ }^{13}$ See 'Lesser Degrees of Explanation' (Scheall, 2015d) for a discussion of Hayek's mostly implicit 'theory of predictive degree'. A truly precise prediction of a particular event - i.e, a prediction of degree 1 - would rule out all but one event and would be falsified by the appearance of any of the prohibited events. To say that explanations of the principle and pattern predictions are of lesser degree is to say that they rule out fewer events and, thus, are more difficult to falsify.

${ }_{14}$ ' $[T]$ here seems to exist a fairly easy and abstract way to measure the degree of complexity of different kinds of abstract patterns. The minimum number of elements of which an instance of the pattern must consist in order to exhibit all the characteristic attributes of the class of patterns in question appears to provide an unambiguous criterion...[W]hen we consider the question from the angle of the minimum number of distinct variables a formula or model must possess in order to reproduce the characteristic patterns of structures of different fields (or to exhibit the general laws which these structures obey), the increasing complexity as we proceed from the inanimate to the ('more highly organized') animate and social phenomena becomes fairly obvious' (Hayek, 1964a [1967], p. 25-26).
} 


\section{The Failure of Hayek's Early Theory of the Cycle and his Response}

Hayek eventually came to recognise the chief defect of his early business-cycle project to be an incompatibility between the complexity of economic-cyclical phenomena and the limited explanatory capacities of the extant analytical tools. In the introductory sections of The Pure Theory of Capital - the culminating piece of his technical research program on the trade cycle - Hayek (1941 [2007]) acknowledged that, despite the tremendous intricacy of the models developed therein, The Pure Theory was not nearly elaborate enough to express the complexity of the phenomena under investigation. In order to appreciate this point, it is important to review the difficulties Hayek encountered in the development of the businesscycle project that was so very central to his early career as an economic theorist.

Hayek's earliest writings in technical economics ${ }^{15}$ aimed to clarify the foundations of the theoretical framework upon which he would build the trade-cycle theory exposited in the companion pieces Monetary Theory and the Trade Cycle (Hayek, 1933 [2008]; originally published in German in 1929) and Prices and Production (Hayek, 1931; 1935 [2008]). It was the development of an appropriate concept of intertemporal equilibrium and, later, a theory of capital adequate to the problem of industrial fluctuations that would prove most intractable in this regard.

Hayek (1928 [1984]) was quite aware that Walras' static general equilibrium framework was an imperfect tool upon which to base a theory of the cycle in a dynamic, money- and capital-using economy. Nonetheless, when he came to consider the methodology of cycle theories in Monetary Theory, he argued that the goal of unifying an explanation of the cycle with the then-accepted corpus of economic theory required the Walrasian framework (Hayek, 1933 [2008], pp. 18-19). The uniqueness of Hayek's early theory lies in the fact that, with the introduction of assumptions concerning money and the activities of bankers in the creation of credit, cyclical fluctuations can be generated out of an otherwise perfectlyadjusting equilibrium framework.

However, in the 1933 essay 'Price Expectations, Monetary Disturbances, and Malinvestments', Hayek (1933 [1984], p. 136) argued against this view that the superimposition of monetary assumptions on the skeleton of Walrasian equilibrium sufficed to generate an adequate explanation of the cycle. This method 'press[es] the problems into the strait-jacket of a scheme which does not really help to solve them'. Instead, what was needed was 'a development of our fundamental theoretical apparatus which will enable us to explain dynamic phenomena...l am now more inclined to say that general theory itself ought to be developed so as to enable us to use it directly in the explanation of particular industrial fluctuations' (Hayek, 1933 [1984], pp. 137-138). A new treatment of 'general theory' - i.e., equilibrium theory - was necessary to account for cyclical phenomena.

Hayek (1937 [1948]) subsequently developed, in 'Economics and Knowledge,' the unique conception according to which equilibrium exists to the extent that the relevant beliefs of individual market participants are both inter-subjectively consistent and accurate with respect to external conditions. He employed this framework throughout The Pure Theory of Capital, but '...repeatedly apologizes for doing so. Although he clearly considers the new definition to be an advance over those found in earlier models, he also suggests that equilibrium analysis in general is, at best, preparatory to a more advanced causal analysis of economic phenomena' (Caldwell, 2004, p. 224; italics in the original; also see Chapter Two of Hayek, 1941 [2007], pp. 31-51). That is, Hayek judged his epistemic concept of equilibrium,

\footnotetext{
${ }^{15}$ These early essays have been translated and anthologised, either in Hayek (1984) or in the relevant volumes of Hayek's Collected Works.
} 
more suitable though it was than the traditional treatment, to be yet too simple for a full explanation of fluctuations.

Beyond its inadequate equilibrium-theoretical foundations, Prices and Production incorporated Böhm-Bawerk's concept of the 'average period of production', a measure of the temporal duration of the economy's capital structure. It was this element that was to receive the harshest criticism from both Hayek and his peers in the years following the initial articulation of the early cycle theory. As Hayek soon came to recognise, it is possible to define an average period of production without circularity only under severely restricted assumptions. When these conditions are relaxed, the definition of the average production period becomes circular in that it is both determined by, and a determinant of, the interest rate (Hayek, 1936 [2008], pp. 497-498; White, 2007, p. xxii).

The theory of fluctuations offered in Prices and Production was intended to be - and, given the circumstances of its rushed preparation, could only be - a mere sketch of an elaborated explanation of the cycle. ${ }^{16}$ But, as it became clear that the simplifications of the latter book, especially with regard to the temporal element embodied in the period of production concept, 'evaded so many essential problems that the attempt to replace it by a more adequate treatment...raised a host of new questions which had never been really considered and to which answers had to be found' (Hayek, 1941 [2007], p. 4), Hayek was unable to proceed immediately to a more detailed account of the cycle. The theory of capital upon which the analysis of Prices and Production was founded was too simple: 'I can see in the simplified form in which I had to use it in my former book it may be more misleading than helpful' (Hayek, 1939, p. 7; quoted in White, 2007, p. xxii). The consequences of the simplifications of Prices and Production, especially with regard to capital, could not be ignored (Hayek, 1941 [2007], p. 4).

The further theoretical gaps in Prices and Production include, but are not limited to, a theory of the bust or depression phase of the cycle, or as Hayek (1932 [1984], p. 137) called it, a theory of the 'economics of decline', and a theory of what it means to maintain capital intact over time. Hayek attempted to settle this latter question on a number of occasions (see Hayek, 1935 [1939]; 1936 [2008]; 1941 [2007]). Indeed, he dedicated the better part of the 1930s to reconstructing Böhm-Bawerk's theory of capital so as to make it a more appropriate basis for an explanation of the cycle. Hayek's initial reaction to the shortcomings of his early cycle theory was to attempt to develop a model complicated enough to account for the complexity of the phenomena.

However, Hayek was far from satisfied with the results of this protracted endeavour. The preface to The Pure Theory of Capital is little more than an extended apology for the inadequacies of the theory developed therein despite its massive complexity. In particular, Hayek (1941 [2007], p. 5) perceived the flaws of The Pure Theory to lie 'in the fact that...it leaves some problems of real importance unsolved'. Though '[i]t would undoubtedly be highly desirable...that this should be done once and for all...I can only plead that I have grappled honestly and patiently with what even now appears to me to be by far the most difficult part of economic theory, and that the present book with all its shortcomings is the outcome of work over a period so prolonged that I doubt whether further effort on my part would be repaid by the results' (Hayek, 1941 [2007], p. 5). Indeed, the limited discussion of the trade cycle such as it appears in the fourth part of The Pure Theory remains 'condensed and sketchy' (Hayek, 1941 [2007], p. 5) despite the fact that an elaboration of an improved theory of the cycle was the original motivation for writing the book!

\footnotetext{
${ }^{16}$ On the circumstances of the hurried preparation of Hayek's invited LSE lectures in 1931 (ultimately published later in the same year as Prices and Production), see Hayek (1931; 1935 [2008], pp. 191-196) and Caldwell (2004, pp. 171-173).
} 
For Hayek, in the last analysis, attempting to explain the cycle by way of sufficiently complex analytical tools led only to a theory that nevertheless remained too simple to adequately account for the complexity of the phenomena - and which was, for this reason, 'probably of necessity false' (Hayek, 1964a [1967], p. 28) - while at the same time being 'so damned complicated it's almost impossible to follow' (Hayek, 1994, p. 141). Stated plainly, it seems that Hayek's early business-cycle project failed to bear the fruit he expected of it (at least in part) because, while still failing to express the complexity of the phenomena, the analysis he developed started to outrun his cognitive capacity to keep track of it. Hayek had taken the extant tools as far as he could - which may have been as far as they could have been taken by anyone - but not far enough to complete the capital theory project, much less the elaborated theory of the cycle. ${ }^{17}$ Of course, failure is what we should expect when tools appropriate only for the analysis of simpler phenomena are applied to more complex phenomena. Hayek's methodology implies an explanation of the failure of his early business cycle project.

Beyond this, as we have seen, Hayek's methodology implies that the proper response to such complexity-induced failure is the development of a more general, albeit less testable, higher-level explanation of the principle that permits the theorist to abstract from some of the complexity of the phenomena under investigation. Hayek's epistemic theory represents just such a higher-level explanation. With respect to the causal role each assigns to action based on inadequate knowledge, the epistemic theory includes his early theory of the cycle as a special case - i.e., the epistemic theory is more general than Hayek's interwar theory. This move (which I'm not arguing was necessarily a conscious or deliberate one ${ }^{18}$ ) allowed Hayek to rise above the very intricate details that weighed so heavily upon his early account. Whatever the possible demerits of the epistemic theory of economic fluctuations, it certainly abstracts from many of the intractable intricacies - particularly those concerning capital (which figures nowhere in the epistemic theory) - that undermined Hayek's technical economic account of the cycle.

It is interesting to note the central role that Hayek's 'methodology of sciences of complex phenomena' plays in the epistemic theory itself. Recall that the latter is built upon Hayek's epistemic conception of economic order, his treatment of the price system as a knowledge-coordinating mechanism, and his argument that scientistic methodology encourages policymakers to interfere with the price system, and thereby, to interrupt its epistemic function. According to Hayek's (1975 [1978]) argument in 'The Pretence of Knowledge', scientism treats the very complex phenomena of economic equilibrium as if they are simpler than they are in fact. The methodological element in Hayek's epistemic theory attributes episodes of disequilibrium to action, under the pretence that the complexities of economic phenomena are cognitively tractable with the standard tools of technical economic

\footnotetext{
17 This raises the interesting question whether Hayek would have adopted the more sophisticated analytical tools of, say, modern complex systems theory, had they been available at the time. This is a difficult counterfactual to evaluate if for no other reason than that Hayek did not seem to possess the competency required to fruitfully apply the most sophisticated mathematical tools of his own day, much less some yet more refined tools that would not be developed for a half-century following his emigration from the field of technical economics. Who knows what Hayek would have done if both he had been sufficiently adept and more advanced tools had been available during the 1930s?

${ }^{18}$ Hayek's epistemology emphasises the crucial role of knowledge of which we are not 'explicitly aware', but that we 'merely manifest...in the discriminations which we perform' (Hayek, 1952, p. 19). This is 'tacit' knowledge (Polanyi, 1966) or 'knowledge how' as opposed to 'knowledge that' (Ryle, 1946). Given the prominent role that Hayek assigns to tacit knowledge, it is perfectly in keeping with his epistemology that his development of the more general, less testable, epistemic theory was not a purposeful response to the failure of his early cycle theory. It is possible that Hayek's shift to the epistemic theory was merely manifest in the discriminations he performed and that he was not explicitly aware of the consistency of this shift with his methodology.
} 
analysis. More to the point, Hayek's argument is that action - usually, political action intended to maintain (or restore) a state of economic equilibrium, or of 'full employment', which is founded on belief in a simpler-than-required theory of the economy, is likely to interfere with the equilibrating tendency of the price system and, thus, to lead further away from, rather than closer to, equilibrium.

This move to the higher-level epistemic theory involves a shift from the theoretical plane of generalisations about economic phenomena, to the methodological plane of generalisations about the former kind of theoretical generalisations. Hayek's methodology of sciences of complex phenomena, which takes as its elements the relations between theories and their elements, is of a yet higher order than the theories it encompasses. ${ }^{19}$ The elements of the epistemic theory are not themselves economic phenomena, but beliefs about economic phenomena and the mechanisms by which such beliefs might be coordinated. ${ }^{20}$ Thus, the methodology of sciences of complex phenomena both explains, and can be interpreted as, a reaction to the failure of Hayek's early business cycle project.

\section{Concluding Remarks: The Implications of the Argument for the Literature on Hayek's 'Transformation'}

The present paper is the second part of a multi-essay project that addresses, and aims to account for, various continuities and discontinuities in Hayek's thought concerning the business cycle. In the first part of this project - 'Hayek's Epistemic Theory of Industrial Fluctuations' (Scheall, 2015b) - I argue that Hayek's concern for the causal role in propagating economic fluctuations of actions based on an inadequate epistemic foundation was continuous (and only became more general) over the arc of his career, but that he adopted distinct tools at different times to account for the causes and economic effects of ignorant action. In the present paper, I have attempted to show that Hayek's own methodology of sciences of complex phenomena implies an explanatory principle that reconciles both the former permanence and the latter break in Hayek's intellectual development. When a scholar attempts to account for massively complex phenomena such as those of industrial fluctuations with tools appropriate only for the explanation of simpler phenomena, the proper response is the development of a more general, higher-level, explanation of the principle such as Hayek's epistemic theory of industrial fluctuations.

In this concluding section, it remains merely to draw out the implications of this multiessay project for the secondary literature on Hayek's transformation. First, a brief overview of this literature - or, at least, of its 'greatest hits' - is in order. The existing secondary canon divides fairly neatly between arguments for an irreconcilable break in Hayek's intellectual development, and interpretations of Hayek's writings as essentially consistent across a broad swathe of his career.

Terence Hutchison (1981) was the first to posit a fundamental discontinuity in Hayek's thought. According to Hutchison, 'Hayek l' was (something like) a Misesian

\footnotetext{
19 "The term "higher level regularities" which I have used to describe the content of such statements about the general character of an order is meant to indicate that it does not refer to relations between particular elements of such an order, but only to relations between relations, or even relations between relations between relations between the elements' (Hayek, 1961 [2014], p. 381).

${ }^{20}$ However, this being said, although Hayek's epistemic theory is a 'higher-level' account, it remains entirely a micro explanation and does not run afoul of Hayek's well-known distaste for macro explanations of social phenomena (for evidence of this antipathy, see, e.g., Hayek, 1975 [1978]). The epistemic account explains fluctuations in terms of the conditions necessary to coordinate the beliefs, and of the causes and effects of the ignorant actions of, individual actors, and makes no attempt to aggregate, index, or average beliefs across multiple actors.
} 
methodological apriorist, while 'Hayek II' favoured a methodology more in line with Popperian philosophy of science. ${ }^{21}$ In the early 1990s, Bruce Caldwell engaged in a somewhat tendentious debate with Hutchison concerning the 'Hayek II' thesis (Caldwell, 1988; 1992a; 1992b; for Hutchison's response, see Hutchison, 1992; and for Caldwell's later reflections on the 'skirmish', see Caldwell, 2009). Caldwell rejected Hutchison's particular taxonomy, but not the notion that there was a significant discontinuity in Hayek's thought. According to Caldwell (1988; 2004), Hayek's transformation consisted of a rejection of the standard notion of equilibrium in favour of the epistemic conception of economic order. Like Caldwell, Nicolai Juul Foss (1995) argued that Hayek traded the customary treatment of equilibrium for the epistemic conception, but insisted that this transformation was more subtle and less sudden than Caldwell would have it.

Several other scholars have made notable contributions to the 'fundamental discontinuity' side of the secondary literature. Steve Fleetwood (1995) posited three different 'Hayeks' distinguished in terms of unique ontological attitudes that Hayek allegedly adopted at different times. Ulrich Witt (1997) defended an account of industrial fluctuations consistent with Hayek's theory of spontaneous orders, but argued for a discontinuity between these aspects, as developed in Hayek's own writings. According to Jack Birner (1999), Hayek's 'epistemic turn' consisted of the rediscovery and subsequent emphasis of themes prevalent in Hayek's (1920 [1991]) early work on cognitive psychology that were largely ignored in his technical economics. More recently, Erwin Dekker (2014) has argued that the several social cataclysms of the interwar years (and immediately after) led to an extension of Hayek's curricular interests beyond technical economics.

On the other side of this division reside arguments that aim to establish the fundamental unity of Hayek's intellectual development. Perhaps the most well-known and representative example of this literature is Gerald O'Driscoll's (1977) Economics as a Coordination Problem. Recent excursions to the Hayek archives at Stanford University's Hoover Institution have led Bruce Caldwell (Manuscript) to cast some doubt on his prior thesis concerning Hayek's once-and-for-all rejection of the toolbox of the technical economist. Peter Boettke (2015) has argued, not only for the continuity of Hayek's methodological thought, but also, for its fundamental consistency with Mises's methodological project.

Regardless of the obvious significance of several of these contributions, it is part of the purpose of the present multi-essay project to exhibit certain fundamental weaknesses in the secondary literature on Hayek's intellectual development. In the concluding section of

\footnotetext{
${ }^{21}$ As indicated in the introductory section of the present essay, I argue in 'Hayek the Apriorist?' (Scheall, 2015a) that Hutchison's 'Hayek I' thesis is untenable. Hayek and Mises defended mutually inconsistent notions of a priori knowledge such that, even if Hayek had accepted methodological apriorism (a claim he always denied), it would have meant something different to him than it meant to Mises. Jeffrey Friedman (2013) has recently argued that Hayek held multiple mutually-inconsistent epistemologies at different times in his career. This too is an untenable thesis. In order to accept Friedman's argument that there is an inconsistency between the fallibilist-'interpretivist' epistemology of The Sensory Order (Hayek, 1952) and the (allegedly) infallibilist-'non-interpretivist' epistemology of 'The Use of Knowledge in Society' (Hayek, 1945 [1948]), one has to believe, not only that Hayek changed his epistemological views between 1945 and 1952, but also that he was almost quite literally schizophrenic in his everdithering epistemological attitudes. Hayek's fallibilism in The Sensory Order is also apparent in the 1920 essay (Hayek, 1920 [1991]) upon which (as Friedman acknowledges) it was explicitly based. So, either (as implied by Friedman's argument) Hayek was a fallibilist in 1920, an infallibilist in 1945, and a fallibilist again in 1952, or - as seems far more likely - when Hayek wrote of 'knowledge' in the 1945 essay, he intended the word in its fallibilist sense and Friedman's interpretation of Hayek as an infallibilist in the same essay is a misreading. If this is right, then the inconsistency alleged (and the epistemological schizophrenia implied) by Friedman disappears. In any case, either Hutchison or Friedman (or, I would argue, both) must be wrong: Hutchison argued that Hayek only became a thoroughgoing fallibilist with the publication of "Economics and Knowledge" in 1937 (Hayek, 1937 [1948]) and remained one for the balance of his career; Friedman claimed that Hayek was a fallibilist over the entire course of his career with the exception of a brief infallibilist interlude in 1945.
} 
'Hayek's Epistemic Theory', I defend the view that the paper bears no significant implications for the question whether Hayek's thought was more or less continuous across time. My point there was that, in a career as long and multifaceted as Hayek's, we should expect to observe neither maximal unity nor utter chaos. All we can do, then, is to argue whether Hayek's development was more or less continuous though the years. However, no one in the relevant secondary literature has offered a standard or definition of continuity according to which the degree of diachronic unity of Hayek's thought might be inter-subjectively evaluated. In the absence of some such standard, there can be no (knowable) fact of the matter concerning the degree to which Hayek 'transformed' beyond the arguments of his youth: 'there are only [unstated] competing definitions of continuity according to which the question is answered in different ways, and [implicit] judgments of value as to which definitions are more acceptable than others. Such arguments are more likely to reflect the interests of the individual scholars who defend them than anything of significance for Hayek's career' (Scheall, 2015b, pp. 118-119)..$^{22}$

The present paper establishes two points of further relevance to an immanent criticism of the secondary literature on Hayek's intellectual development. First, as should be apparent from the argument of the present paper, several of the central contributions to this literature can at best be considered preparatory to a more advanced analysis. Even if we possessed some definition of general intellectual continuity by which related judgments might be inter-subjectively appraised, to leap from an argument for this particular continuity or that specific discontinuity in Hayek's thought to some more general conclusion, would remain dubious so long as the possibility remained open of unifying these disparate elements in terms of some explanatory principle. If some such principle could be discovered in Hayek's own methodological writings, then all to the better for a higher-order unification of his canon.

The same principle adduced in the current paper to reconcile the continuous and discontinuous aspects of the development of Hayek's thought concerning industrial fluctuations, is capable of similarly unifying other apparently incongruent elements posited in the secondary literature. Consider the seeming inconsistency between O'Driscoll's (1977) argument for the continuity of the development of Hayek's writings on spontaneous order out of the early business-cycle project, and Caldwell's $(1988 ; 2004)$ argument that Hayek rejected the general equilibrium framework of his early theory of fluctuations for a fundamentally inconsistent conception of economic order as coordinated knowledge. The continuity posited by O'Driscoll regarding Hayek's unending concern for the coordination and dis-coordination of knowledge, would seem to be easily reconcilable with the break posited by Caldwell in the different conceptions of economic equilibrium / order. The Walrasian treatment of general equilibrium was inadequate relative to the epistemic conception of economic order for the elucidation of the causes and effects of knowledge dis-coordination, so - in keeping with the principle that a scholar whose concerns outrun the capacities of the extant tools of analysis must settle for a more general, higher-order, explanation of the principle - Hayek traded the Walrasian concept for the epistemic one.

\footnotetext{
${ }^{22}$ Given the contentious nature of both the topics that Hayek typically engaged and his distinctive arguments, it should be explicitly acknowledged that there is political value in any answer to the question concerning the continuity of these arguments. If it could be established that Hayek argued indiscriminately, with little internal consistency across time, it would seem to provide some, albeit perhaps weak, grounds to those inclined to dismiss his perspective(s); but, by the same token, this move from the discontinuity of Hayek's canon to a rejection of one or more of his positions would be blocked if it could be shown that Hayek's arguments were in fact continuous throughout his career. Alternatively, if one likes some aspect(s) of Hayek's writings more than some other(s), the transformation question fuels arguments that his thought either evolved or devolved beyond his early views.
} 
Similarly, consider the inconsistency between Birner's (1999) thesis that the epistemological themes of Hayek's (1920 [1991]; 1952) cognitive psychology, which figure centrally in his later work, are absent from his early business-cycle project, and my own claim in 'Hayek's Epistemic Theory' (Scheall, 2015b) that epistemic considerations are important to the early business-cycle project, albeit not emphasised to the extent they came to be in the epistemic account of industrial fluctuations. Again, it may well be that these theses are less at odds than they appear at first glance. It is quite possible that epistemic concerns were omnipresent throughout Hayek's career, but that because the Walrasian equilibrium construct at the heart of the early cycle theory was a tool too simple to express the complexity of the phenomena of human ignorance, these epistemic concerns were minimised in the early account. We might then interpret Hayek's awkward (and somewhat ad hoc) attempt to shoehorn bankers' ignorance of the natural rate of interest into the early theory, as a doomed effort to deal with the causes and effects of the complex phenomena of human ignorance with tools far too simple for such an analysis. Needless to say, Hayek's epistemic conceptions of both economic order and the price system, as well as his anti-scientistic methodology of sciences of complex phenomena, are both better suited to the complexity of human ignorance and emblematic of the principle that explanatory progress is possible under circumstances of complexity-induced failure only if the scholar settles for a more general, less testable, higher-order explanation. Thus, the apparent inconsistency between Birner's account and my own disappears when examined through the lens of the relevant Hayekian methodological principle.

Beyond this failure to seek explanatory principles that might unify seemingly irreconcilable aspects of Hayek's intellectual development, the present paper points to a second shortcoming of the secondary literature. There is a tendency, in attempts to explain (some aspect or other of) Hayek's career, to try to go beyond the sort of limited explanations of the principle that Hayek himself thought were possible in the sciences of complex phenomena. That is, there is a tendency to pretend to a full explanation of (some aspect or other of) Hayek's career, where only a limited explanation of the principle may be possible.

There are several reasons to think that the phenomena of Hayek's career - and the phenomena of scholarly inquiry, more generally - qualify as complex in Hayek's sense. First, Hayek argued that all mental phenomena are complex in the relevant sense. Thus, to the extent that the phenomena of scholarly inquiry are mental phenomena, they qualify as complex. Second, Hayek argued for the complexity of social phenomena. So, to the extent that the phenomena of scholarly inquiry are social, they qualify as complex. ${ }^{23}$ Moreover, if these phenomena are a consequence of some combination of mental and social phenomena - an assumption that seems perfectly reasonable - then the phenomena of scholarly inquiry must be yet more complex than if they were either purely mental or purely social. A full explanation of the phenomena of scholarly inquiry would have to account, not only for the complexity of their mental elements and their social elements in isolation, but also for the interactions of these elements. ${ }^{24}$ Thus, a full explanation of any particular aspect of Hayek's career - much less of its entirety - would seem to be impossible on Hayek's own lights.

If this is right, then any attempt to explain some part of Hayek's intellectual development must be accompanied with a frank acknowledgement of the limits of such an

\footnotetext{
${ }^{23}$ See footnote 11 above. Both theoretical psychology and the social disciplines qualify as sciences of complex phenomena.

${ }^{24}$ The possibility that the investigation of scholarly inquiry - i.e., methodology itself - might be, in Hayek's sense, a science of complex phenomena is explored in my unpublished manuscript 'Kinds of Scientific Rationalism: The Case for Methodological Liberalism' (Scheall, Manuscript).
} 
explanation. ${ }^{25}$ More to the point, if we are limited to explanations of the principle of this or that aspect of Hayek's career, the question whether his intellectual development was more or less continuous would seem to evaporate. We can't fully explain this development in its entirety, but are limited to explanations of the principle of particular aspects of Hayek's career. No more general conclusion can be legitimately inferred, given our limited theoretical and empirical knowledge of the mental and social circumstances from which Hayek's scholarly arguments emerged.

\section{Acknowledgements}

The present paper was conceived during the 2013-2014 academic year while I was a Research Fellow with Duke University's Center for the History of Political Economy. The paper is dedicated to my friend (and HOPE Center co-fellow) Gerardo Serra, who first suggested to me the need for, and potential fruitfulness of, an analysis of Hayek's work from its own perspective. It was only then that I realised that such was the nature of a project upon which I had, without fully appreciating its significance, already embarked. Gerardo's suggestion was an enormous aid in the development of the project. I would also like to thank Paul Lewis, Anthony Endres, and Erwin Dekker for helpful comments on earlier drafts, as well as the audience members of a session at the 2014 History of Economics Society conference in Montreal. As much as I might like to blame one or more of the forenamed for my own mistakes, any errors left uncorrected in the present essay are, unfortunately, my own.

\section{References}

Birner, J. (1999) 'The Surprising Place of Cognitive Psychology in the Work of F.A. Hayek.' History of Economic Ideas, 7(1-2), pp. 43-84.

Boettke, P. (2015) 'The Methodology of Austrian Economics as a Sophisticated, Rather Than Naïve, Philosophy of Economics.' Journal of the History of Economic Thought, 37(1), pp. 79-85.

Caldwell, B. (1988) 'Hayek's Transformation.' History of Political Economy, 20(4), pp. 513-541.

Caldwell, B. (1992a) 'Hayek the Falsificationist?' Research in the History of Economic Thought and Methodology, 10, pp. 1-15.

Caldwell, B. (1992b) 'Reply to Hutchison.' Research in the History of Economic Thought and Methodology, 10, pp. 33-42.

Caldwell, B. (2004) Hayek's Challenge: An Intellectual Biography of F.A. Hayek. Chicago: University of Chicago Press.

Caldwell, B. (2009) 'A Skirmish in the Popper Wars: Hutchison versus Caldwell on Hayek, Popper, Mises, and Methodology.' Journal of Economic Methodology, 16(3), pp. 315-324.

\footnotetext{
${ }^{25}$ Alternatively, of course, it might be argued either that the phenomena of scholarly inquiry - and, therefore, of Hayek's intellectual development - do not qualify as complex phenomena or that, complex though these phenomena may be, Hayek was simply wrong about the impossibility of full explanations of complex phenomena. Needless to say, no such arguments appear anywhere in the literature concerned with explaining Hayek's transformation.
} 
Caldwell, B. (Manuscript) 'F.A. Hayek and "The Economic Calculus"': The Cambridge and Virginia Lectures.

http://hope.econ.duke.edu/sites/default/files/FA\%20Hayek\%20and\%20the\%20Economic\%20 Calculus.pdf.

Dekker, E. (2014) The Viennese Students of Civilization: Humility, Culture and Economics in Interwar Vienna and Beyond. Erasmus University Rotterdam.

Fleetwood, S. (1995) Hayek's Political Economy: The Socio-economics of Order. London: Routledge.

Foss, N.J. (1995) 'More on "Hayek's Transformation”.' History of Political Economy, 27(2), pp. 345-364.

Friedman, J. (2013) 'Hayek's Two Epistemologies and the Paradoxes of His Thought.' Critical Review, 25(3-4), pp. 277-304.

Hayek, F.A. (1920 [1991]) 'Contributions to a Theory of How Consciousness Develops.' (Trans.) G. Heinz. Hoover Institution, Hayek Archives, Box 92, Folder 1.

Hayek, F.A. (1928 [1984]) 'Intertemporal Price Equilibrium and Movements in the Value of Money,' in McCloughry, R., ed., Money, Capital, and Fluctuations: Early Essays. Chicago: The University of Chicago Press, pp. 71-117.

Hayek, F.A. (1931, 1935 [2008]) 'Prices and Production,' in Salerno, J., ed., Prices and Production and Other Works. Auburn, AL: Ludwig von Mises Institute, pp. 189-329.

Hayek, F.A. (1932 [1984]) 'Capital Consumption,' in McCloughry, R., ed., Money, Capital, and Fluctuations: Early Essays. Chicago: The University of Chicago Press, pp. 136-158.

Hayek, F.A. (1933 [1939]) Price Expectations, Monetary Disturbances, and Malinvestments. In Profits, Interest, and Investment. New York: Augustus M. Kelley, pp. 135-156.

Hayek, F.A. (1933 [1984]) 'On "Neutral Money"', in McCloughry, R., ed., Money, Capital, and Fluctuations: Early Essays. Chicago: The University of Chicago Press, pp. 159-162.

Hayek, F.A. (1933 [2008]) 'Monetary Theory and the Trade cycle,' in Salerno, J., ed., Prices and Production and Other Works. Auburn, AL: Ludwig von Mises Institute, pp. 1-130.

Hayek, F.A. (1935 [1939]) The Maintenance of Capital. In Profits, Interest, and Investment. New York: Augustus M. Kelley, pp. 83-134.

Hayek, F.A. (1936[2008]) 'The Mythology of Capital,' in Salerno, J., ed., Prices and Production and Other Works. Auburn, AL: Ludwig von Mises Institute, pp. 487-520.

Hayek, F.A. (1937 [1948]) Economics and Knowledge. In Individualism and Economic Order. Chicago: University of Chicago Press, pp. 33-56.

Hayek, F.A. (1939). Profits, Interest, and Investment. In Profits, Interest, and Investment. New York: Augustus M. Kelley, pp. 3-71.

Hayek, F.A. (1941[2007]) 'The Pure Theory of Capital,' in White, L., ed., The Collected Works of F.A. Hayek, vol. 12, The Pure Theory of Capital. Chicago: University of Chicago Press.

Hayek, F.A. (1945[1948]) The Use of Knowledge in Society. In Individualism and Economic Order. Chicago: University of Chicago Press, pp. 77-91.

Hayek, F.A. (1952) The Sensory Order: An Inquiry into the Foundations of Theoretical Psychology. Chicago: University of Chicago Press.

Hayek, F.A. (1961[2014]) 'A New Look at Economic Theory,' in Caldwell, B. ed., The Collected Works of F.A. Hayek, vol. 15, The Market and Other Orders. Chicago: University of Chicago Press, pp. 375-426.

Hayek, F.A. (1964a[1967]) The Theory of Complex Phenomena. In Studies in Philosophy, Politics, and Economics. Chicago: University of Chicago Press, pp. 22-42. 
Hayek, F.A. (1964b[1967]) Kinds of Rationalism. In Studies in Philosophy, Politics, and Economics. Chicago: University of Chicago Press, pp. 82-95.

Hayek, F.A. (1967) Notes on the Evolution of Systems of Rules of Conduct. In Studies in Philosophy, Politics, and Economics. Chicago: University of Chicago Press, pp. 66-81.

Hayek, F.A. (1975[1978]) The Pretence of Knowledge. In New Studies in Philosophy, Politics, Economics, and the History of Ideas. Chicago: University of Chicago Press, pp. 23-34.

Hayek, F.A. (1984) Money, Capital, and Fluctuations: Early Essays. McCloughry, R., ed., Chicago: The University of Chicago Press.

Hayek, F.A. (1994) Hayek on Hayek: An Autobiographical Dialogue. Kresge, S. and Wenar, L. eds. Chicago: University of Chicago Press.

Hutchison, T.W. (1981) The Politics and Philosophy of Economics: Marxians, Keynesians, and Austrians. Oxford: Blackwell.

Hutchison, T.W. (1992) 'Hayek and "Modern Austrian" Methodology: Comment on a NonRefuting Refutation.' Research in the History of Economic Thought and Methodology,10, pp. 17-32.

O'Driscoll, G. (1977) Economics as a Coordination Problem. Menlo Park, CA: Institute for Humane Studies.

Polanyi, M. (1966) The Tacit Dimension. Garden City, NY: Doubleday \& Company, Inc.

Ryle, G. (1946) 'Knowing How and Knowing That.' Proceedings of the Aristotelian Society. 46, pp. 1-16.

Scheall, S. (2015a) 'Hayek the Apriorist?' Journal of the History of Economic Thought, 37(1), pp. 87-110.

Scheall, S. (2015b) 'Hayek's Epistemic Theory of Industrial Fluctuations.' History of Economic Ideas, XXIII(1), pp. 101-122.

Scheall, S. (2015c) 'A Brief Note Concerning Hayek's Non-Standard Conception of Knowledge.' Review of Austrian Economics. Issue TBD, published online March 18, 2015.

Scheall, S. (2015d) 'Lesser Degrees of Explanation: Further Implications of Hayek's Methodology of Sciences of Complex Phenomena.' Erasmus Journal for Philosophy and Economics, 8(1), pp. 42-60.

Scheall, S. (Manuscript) 'Kinds of Scientific Rationalism: The Case for Methodological Liberalism.' http://papers.ssrn.com/sol3/papers.cfm?abstract id=2619311

White, L. (2007) 'Editor's Introduction,' in White, L., ed., The Collected Works of F.A. Hayek, vol. 12, The Pure Theory of Capital. Chicago: University of Chicago Press, pp. xiii-xxxvi.

Witt, U. (1997) 'The Hayekian Puzzle: Spontaneous Order and the Business Cycle.' Scottish Journal of Political Economy, 44 (1), pp. 44-58. 